\title{
Research on Contribution Rate Measurement of Education on Economy Based on Fuzzy Neural Network Model
}

\author{
Junying Tan \\ School of Public Administration, Guizhou University of Finance and Economics, Guizhou 550025, \\ China \\ junyingtan@163.com
}

\begin{abstract}
In this paper, the fuzzy theory and neural network theory to blend together, based on fuzzy neural network model to measure the economic contribution of education, through three stages of index selection and neural network training, the final empirical results show that education for China's economic development has a significant role in promoting.
\end{abstract}

Keywords: fuzzy theory; neural networks; investment in education; economic growth; contribution.

\section{Build the model}

The impact of the education on economic growth is typical social issues and economic issues. Its complexity makes some deterministic mathematical methods are difficult to apply, even in many cases we cannot build a structural model to determine the relationship between the two. In this case, the fuzzy theory and neural network method is more applicable, especially in the new millennium, in the fuzzy theory to the study of evaluation in education economic contribution application more and more common. Based on this, this paper combined two methods; construct the fuzzy neural network evaluation model, used in education and economic contribution of the research.

Positive steps in this article consist of three levels: first, to build three evaluation parameters set. The first set of evaluation parameters including per capita gross national product; the second set of parameters including the evaluation, the per capita gross national product per capita of fixed assets, human capital, per capita arable land; and the third set of parameters including evaluation, education capital index health capital indicators index experienced capital, human capital indicators. Three parameters set have their own functions, the first evaluation parameter set is used to fuzzy classification of various areas in China, the second set of parameters used to evaluate the linkages between human capital and economic, the third set of evaluation parameters used to establish the link between education and human capital. Secondly, based on neural network method and the first evaluation parameter collection, to our country economic development in different areas of the general classification, because the different economic levels in the region, human capital intensity of the economic impact varied widely. Once again, it is built on the economic level of the same area and the connection between the human capitals to the economic growth model. As for the second evaluation parameters collection, with the characterization of per capita GNP, respectively, characterization per capita fixed assets, human capital, per capita arable land, their relationship as follows:

$$
\begin{array}{r}
G=w_{k 0}+w_{k 1} q_{1}+w_{k 2} q_{2}+w_{k 3} q_{3} \\
\eta=\frac{w_{k 2}}{w_{k 1}+w_{k 2}+w_{k 3}} \times 100 \%
\end{array}
$$

When the formula (1) trained fuzzy neural network model of human capital to economic growth, human capital for economic growth contribution degree can be described by $\eta$. Meanwhile, according to the third set of evaluation parameters and fuzzy neural network training method to build the link between education and human capital. In this case, with representatives of human capital, with $q_{1}, q_{2}$, $q_{3}$, respectively characterization education capital indicators, health indicators of capital, experience capital indicators related to mathematics is described as: 


$$
\begin{aligned}
& \mathrm{R}=w_{k 0}+w_{k 1} q_{1}+w_{k 2} q_{2}+w_{k 3} q_{3} \\
& \varepsilon=\frac{w_{k 2}}{w_{k 1}+w_{k 2}+w_{k 3}} \times 100 \%
\end{aligned}
$$

When training according to the formula (2) the education capital for fuzzy neural network model between human capital, education level of capital for the contribution of human capital can be described by $\eta$. We multiply two contribution parameters $\eta$ and $\varepsilon$ together again, we can get the contribution of education to economic growth.

\section{The empirical analysis of education on economic contribution rate measure}

\section{1 economic level divisions of various regions}

The division of the national regional economic level, we based the GDP per capita in 2013 the country's 31 provinces were zoning. In 2013 and per capita GDP of 31 provinces in China is as shown in table 1.

\begin{tabular}{|c|c|c|c|c|}
\hline Province & $\begin{array}{c}\text { Per capita } \\
\text { GDP (Yuan) }\end{array}$ & $\begin{array}{l}\text { Per capita fixed } \\
\text { assets (million) }\end{array}$ & $\begin{array}{l}\text { Human } \\
\text { Capital }\end{array}$ & $\begin{array}{l}\text { Per capita arable } \\
\text { land (mu) }\end{array}$ \\
\hline Tianjin & 95094 & 5.22 & 1.42 & 0.33 \\
\hline Beijing & 88168 & 2.76 & 1.41 & 0.11 \\
\hline Shanghai & 85647 & 2.11 & 1.82 & 0.10 \\
\hline Jiangsu & 68437 & 3.38 & 1.10 & 0.60 \\
\hline Inner Mongolia & 64417 & 4.18 & 0.79 & 2.88 \\
\hline Zhejiang & 63347 & 2.60 & 0.84 & 0.35 \\
\hline Liaoning Province & 56585 & 4.04 & 1.40 & 0.93 \\
\hline Guangdong & 54325 & 1.62 & 1.04 & 0.27 \\
\hline Fujian Province & 52962 & 2.66 & 1.17 & 0.36 \\
\hline Shandong & 51897 & 2.78 & 0.89 & 0.78 \\
\hline Jilin & 43426 & 2.71 & 1.03 & 2.01 \\
\hline Chongqing & 39257 & 2.56 & 0.65 & 0.77 \\
\hline Hubei & 38642 & 2.18 & 1.00 & 0.81 \\
\hline Shanxi Province & 38609 & 2.52 & 0.55 & 1.08 \\
\hline Hebei & 36701 & 2.26 & 0.87 & 0.87 \\
\hline Ningxia & 36411 & 2.61 & 0.52 & 1.73 \\
\hline Heilongjiang & 35711 & 1.95 & 1.25 & 3.09 \\
\hline Xinjiang & 33800 & 2.10 & 0.90 & 1.87 \\
\hline Shanxi & 33712 & 1.97 & 0.78 & 1.13 \\
\hline Hunan & 33587 & 1.80 & 0.67 & 0.57 \\
\hline Qinghai & 33179 & 2.53 & 0.52 & 0.96 \\
\hline Hainan & 32557 & 1.89 & 0.98 & 0.83 \\
\hline Henan & 31753 & 1.89 & 0.64 & 0.84 \\
\hline Sichuan Province & 29627 & 1.77 & 0.56 & 0.74 \\
\hline Jiangxi Province & 28851 & 2.02 & 0.79 & 0.63 \\
\hline Anhui & 28841 & 2.09 & 0.59 & 0.96 \\
\hline Guangxi & 28054 & 1.72 & 0.56 & 0.91 \\
\hline Tibet & 23032 & 1.71 & 0.43 & 1.20 \\
\hline Yunnan & 22263 & 1.34 & 0.46 & 1.31 \\
\hline Gansu Province & 22037 & 1.55 & 0.44 & 1.82 \\
\hline Guizhou & 19609 & 1.22 & 0.29 & 1.29 \\
\hline
\end{tabular}

Table 1 relevant data of 31 provinces in China, 2013.

Source: 2014, "China Statistical Yearbook."

As can be seen from the data in Table 1, per capita GDP in Tianjin, Beijing, Shanghai, formed the first tier. For other provinces and cities, we take the level of GDP per capita as a dividing line. In 2013, the national per capita GDP was 38,254 Yuan, thus, on which, Jiangsu, Inner Mongolia, Zhejiang, 
Liaoning, Guangdong, Fujian, Shandong, Jilin, Chongqing, Hubei, Shaanxi Province has formed the second tier, under it, Hebei Province, Ningxia Hui Autonomous Region, Heilongjiang Province, Xinjiang Uygur Autonomous Region, Shanxi, Hunan, Qinghai, Hainan, Henan, Sichuan, Jiangxi, Anhui, Guangxi Zhuang Autonomous Region, Tibet Autonomous Region, Yunnan, Gansu, Guizhou Province has become the third echelon. For the three levels of the regional level, we were training three fuzzy neural networks.

\subsection{The contribution of human capital for economic growth}

After the economic level, we respectively in the three levels of province training network, and based on the equation (1) to establish the relationship between human capital and economic growth, and specific training data as shown in Table 1. In Table 1, except for per capita gross national product, we also counted respectively fixed assets, per capita arable land area per capita and human capital. After that, calculated by the method of formula (1), the values obtained are shown in Table 2 . As it can be seen from the calculation results of the analysis, human capital for economic contribution and for the regions of different economic levels have a significant role, for the first horizontal level of the provinces, the contribution is $46 \%$; for the second horizontal level of the provinces, the contribution is $49 \%$; for the third level of the province level, the contribution of up to $64 \%$. This shows that the less developed economic level; the improvement of human capital, the more can play an effective role in promoting.

Table 2 the empirical results of human capital for economic growth Fuzzy Neural Network Training

\begin{tabular}{|c|c|c|c|c|c|}
\hline & & & & & \\
\hline & & Forward Parameter 1 & 0.23 & 0.06 & 0.70 \\
\hline & & Forward Parameter 2 & 7.50 & 11.00 & 3.80 \\
\hline Fuzzy narameters in the & & Forward Parameter 1 & 0.50 & 0.18 & 0.71 \\
\hline preceding paragraph & & Forward Parameter 2 & 5.15 & 5.92 & 7.08 \\
\hline & & Forward Parameter 1 & 0.31 & 0.34 & 0.07 \\
\hline & Ter Lapita ar avie Iantu & Forward Parameter 2 & 3.15 & 3.58 & 21.70 \\
\hline & After the $\mathrm{p}$ & ameter 1 & 0.20 & 0.04 & 0.32 \\
\hline & After the $\mathrm{p}$ & meter 2 & 0.06 & 0.01 & 0.26 \\
\hline гuzzy parameters Dack & After the $\mathrm{p}$ & ameter 3 & 0.11 & 0.09 & 0.35 \\
\hline & After the $p$ & ameter 4 & 0.00 & 0.00 & 0.01 \\
\hline & $w_{k 1}$ & & 0.06 & 0.00 & 0.27 \\
\hline & $w_{k 2}$ & & 0.11 & 0.01 & 0.28 \\
\hline & $w_{k 3}$ & & 0.00 & 0.01 & 0.06 \\
\hline & $w_{k 1}+w_{k 2}+w_{k 3}$ & & 0.17 & 0.02 & 0.62 \\
\hline & $w_{k 1}$ Contribution rate & & $34 \%$ & $20 \%$ & $44 \%$ \\
\hline & $w_{k 2}$ Contribution rate $(\eta)$ & & $64 \%$ & $49 \%$ & $46 \%$ \\
\hline & $w_{k 3}$ Contribution rate & & $2 \%$ & $31 \%$ & $11 \%$ \\
\hline
\end{tabular}


Table 3 the third level associated parametric data

\begin{tabular}{|c|c|c|c|c|}
\hline province & education Capital & health Capital & experience of capital & human Capital \\
\hline Tianjin & 1.04 & 0.50 & 0.13 & 1.42 \\
\hline Beijing & 4.40 & 0.97 & 0.22 & 1.41 \\
\hline Shanghai & 0.31 & 0.82 & 0.17 & 1.82 \\
\hline Jiangsu Province & 4.15 & 0.19 & 0.06 & 1.10 \\
\hline Inner Mongolia & 0.82 & 0.26 & 0.12 & 0.79 \\
\hline Zhejiang & 3.06 & 0.25 & 0.09 & 0.84 \\
\hline Liaoning Province & 2.13 & 0.37 & 0.09 & 1.40 \\
\hline Guangdong & 5.17 & 0.27 & 0.08 & 1.04 \\
\hline Fujian Province & 1.68 & 0.22 & 0.08 & 1.17 \\
\hline Shandong & 3.45 & 0.16 & 0.06 & 0.89 \\
\hline Jilin & 1.30 & 0.31 & 0.07 & 1.03 \\
\hline Chongqing & 0.94 & 0.09 & 0.04 & 0.65 \\
\hline Hubei & 2.41 & 0.18 & 0.07 & 1.00 \\
\hline Shanxi Province & 1.43 & 0.18 & 0.06 & 0.55 \\
\hline Hebei & 2.19 & 0.17 & 0.00 & 0.87 \\
\hline Ningxia & 0.21 & 0.32 & 0.97 & 0.52 \\
\hline Heilongjiang & 1.70 & 0.28 & 0.05 & 1.25 \\
\hline Xinjiang & 1.01 & 0.41 & 0.13 & 0.90 \\
\hline Shanxi & 1.13 & 0.28 & 0.17 & 0.78 \\
\hline Hunan & 2.14 & 0.10 & 0.06 & 0.67 \\
\hline Qinghai & 0.17 & 0.30 & 0.08 & 0.52 \\
\hline Hainan & 0.30 & 0.21 & 0.05 & 0.98 \\
\hline Henan & 2.40 & 0.10 & 0.44 & 0.64 \\
\hline Sichuan Province & 2.19 & 0.10 & 0.05 & 0.56 \\
\hline Jiangxi Province & 1.04 & 0.13 & 0.06 & 0.79 \\
\hline Anhui & 1.53 & 0.09 & 0.05 & 0.59 \\
\hline Guangxi & 1.29 & 0.11 & 0.07 & 0.56 \\
\hline Tibet & 0.09 & 0.41 & 0.05 & 0.43 \\
\hline Yunnan & 1.27 & 0.14 & 0.06 & 0.46 \\
\hline Gansu Province & 0.70 & 0.15 & 0.05 & 0.44 \\
\hline Guizhou & 0.68 & 0.05 & 0.03 & 0.29 \\
\hline
\end{tabular}

\subsection{The contribution of Education for human capital}

Next, let's analyze the contribution of education to human capital, used for the analysis of the third level parameter data as shown in table 3. According to the formula (2), extrapolate further education capital contribution of human capital as shown in Table 4. As it can be seen from the calculation results of the analysis, education investment for the human capital contribution and for different regional economy has a great effect, for the first horizontal level of the provinces, the contribution is $25 \%$; for the second horizontal level of the provinces, the contribution is $29 \%$; for the third level of the province level, the contribution of up to $42 \%$. This shows that the less developed economic level, education to upgrade human capital have a greater role.

\subsection{The contribution of education to economic growth}

Integrated two-stage results of empirical analysis, we can calculate the contribution of integrated education to economic growth, that is, for the advanced economies provinces (first level), the contribution rate is $12 \%$; for moderate economic province (second level), the contribution rate is $14 \%$; for the economically backward provinces (third level), the contribution rate is $29 \%$. 
Table 4 the empirical results of education for fuzzy neural network training human capital

\begin{tabular}{|c|c|c|c|c|c|}
\hline & & & the third level & the second level & the first level \\
\hline \multirow{6}{*}{$\begin{array}{l}\text { Fuzzy parameters in the } \\
\text { preceding paragraph }\end{array}$} & \multirow{2}{*}{ Per capita fixed assets } & Forward Parameter 1 & 0.42 & 0.21 & 0.52 \\
\hline & & Forward Parameter 2 & 2.10 & 4.41 & 3.37 \\
\hline & \multirow{2}{*}{ Human Capital } & Forward Parameter 1 & 0.21 & 0.13 & 0.77 \\
\hline & & Forward Parameter 2 & 8.14 & 5.23 & 4.01 \\
\hline & \multirow{2}{*}{ Per capita arable land } & Forward Parameter 1 & 0.32 & 0.28 & 0.78 \\
\hline & & Forward Parameter 2 & 3.37 & 3.45 & 4.60 \\
\hline \multirow{4}{*}{ Fuzzy parameters back } & \multicolumn{2}{|c|}{ After the parameter 1} & 0.33 & 0.13 & 0.32 \\
\hline & \multicolumn{2}{|c|}{ After the parameter 2} & 0.14 & 0.58 & 0.16 \\
\hline & \multicolumn{2}{|c|}{ After the parameter 3} & 0.09 & 0.07 & 0.24 \\
\hline & \multicolumn{2}{|c|}{ After the parameter 4} & 0.12 & 0.03 & 0.25 \\
\hline \multicolumn{3}{|c|}{$w_{k 1}$} & 0.15 & 0.06 & 0.16 \\
\hline \multicolumn{3}{|c|}{$w_{k 2}$} & 0.09 & 0.07 & 0.23 \\
\hline \multicolumn{3}{|c|}{$w_{k 3}$} & 0.12 & 0.08 & 0.25 \\
\hline \multicolumn{3}{|c|}{$w_{k 1}+w_{k 2}+w_{k 3}$} & 0.35 & 0.21 & 0.65 \\
\hline \multicolumn{3}{|c|}{$w_{k 1}$ Rate of Contribution } & $42 \%$ & $29 \%$ & $25 \%$ \\
\hline \multicolumn{3}{|c|}{$w_{k 2}$ Rate of Contribution $(\varepsilon)$} & $25 \%$ & $34 \%$ & $36 \%$ \\
\hline \multicolumn{3}{|c|}{$w_{k 3}$ Rate of Contribution } & $33 \%$ & $37 \%$ & $38 \%$ \\
\hline
\end{tabular}

\section{Conclusions}

In this paper, the contribution of education to the economy as the core research objective, empirical analysis model was constructed based on fuzzy neural network, and clearly the concrete steps. During the analysis, by three step evaluation parameter selection, by the implementation of a fuzzy neural network iterative process, eventually won the relevant empirical results. The empirical results show that, for different levels of economic areas in China, education is through the living quality of human capital, reached a promoting effect on economic growth. Among them, the smaller provinces in developed economies, the bigger the impact of economic backwardness provinces. This shows that the economic backwardness provinces must improve the quality of education, to ultimately achieve leapfrog economic development.

\section{Reference:}

[1] Hanzong Li. The economic benefits of China's education investment analysis [J]. Educational Research, 2010, 11 (2).

[2] Yuping Cui. The contribution rate of education to economic growth estimation method review [J]. Tsinghua university education research, 2009, 25 (1).

[3] XueHui An. Education economic measure analysis [J]. Journal of higher normal education research, 2011, 11 (3).

[4] Desheng Lai. On education and economic growth of a transaction cost economics to explain [J]. Journal of academic research, 2007, 21 (9).

[5] Jiazeng Wang. Education of China's economic growth impact analysis [J]. Shanghai economic studies, 2012, 33 (2).

[6] Qingqi Shi, Baoting Qin, jing Chen. China's economic growth factor analysis [M]. Beijing: science and technology literature press, 2012.

[7] Qinghong Miao. Some problems in education contribution measure of economic growth [J]. Education Economy, 2012, 24 (5). 